\title{
REFLEXIONES SOBRE LA LIBERTAD RELIGIOSA ANTE LAS RESTRICCIONES IMPUESTAS COMO CONSECUENCIA DEL COVID-19
}

\author{
Fernando Simón Yarza \\ Profesor Titular de Derecho Constitucional \\ Universidad de Navarra
}

\begin{abstract}
Cómo citar este artículo / Citation: Simón Yarza, F. (2020). Reflexiones sobre la libertad religiosa ante las restricciones impuestas como consecuencia del Covid-19. Biglino

Campos, P.; Durán Alba, F. Los Efectos Horizontales de la COVID sobre el sistema constitucional, Colección Obras colectivas, Fundación Manuel Giménez Abad, Zaragoza.
\end{abstract} DOI: https://doi.org/10.47919/FMGA.0C20.0009

SUMARIO: I. INTRODUCCIÓN - II. LA LIBERTAD RELIGIOSA Y DE CULTOS - 1. La situación en España - a) La normativa: examen crítico - b) Atentados contra la libertad religiosa: episodios concretos 2. Observaciones sobre derecho comparado - a) El Tribunal Supremo de Estados Unidos - b) El Tribunal Constitucional Federal alemán - 3. ¿Neutralidad o neopaganismo? La expresión religiosa institucional durante el coronavirus

\section{INTRODUCCIÓN}

Que el coronavirus ha alterado profundamente nuestra vida cotidiana es una obviedad que no precisa una extensa justificación. Desde que, a mediados de marzo, el Gobierno de España declaró el estado de alarma para hacer frente a esta dura pandemia, hemos vivido una restricción de la libertad de movimientos desconocida para la gran mayoría de la sociedad. Se trataba, ciertamente, de una limitación explicable por la catástrofe, una medida extrema de la que existen otros antecedentes en la historia. La justificación que -dejando provisionalmente al margen las discusiones sobre su alcance- ha tenido el confinamiento no quiere decir, desde luego, que el Gobierno de la nación haya actuado ejemplarmente. No quisiera entrar aquí, sin embargo, a enunciar un 
catálogo de abusos y negligencias. Sin perjuicio de la necesidad de una reflexión sobre la gravedad de la crisis política e institucional que estamos viviendo en España, que en buena medida se enmarca en una crisis cultural general de Occidente, el propósito de las páginas que siguen es más limitado, por mucho que tenga que ver con un asunto que está, a mi parecer, en la raíz misma de la crisis occidental aludida ${ }^{1}$.

El objetivo de este estudio consiste en reflexionar sobre el modo en que las medidas destinadas a contener la epidemia han incidido en la libertad religiosa. Es esta una de las libertades más importantes de la persona -la primera libertad, cronológicamente hablando, del Constitucionalismo moderno, si nos fiamos de la reconocida investigación de Jellinek ${ }^{2}$ - y se ha visto afectada de maneras diversas. Tanto por normas como por resoluciones y, en algunos casos, por la actuación material de los agentes públicos. Tanto en España habría que añadir - como en otros países de nuestro entorno cultural. En el contexto global en que nos movemos, merecen una mención específica algunas decisiones adoptadas por tribunales extranjeros, en particular las resoluciones dictadas al respecto por el Tribunal Supremo de los Estados Unidos y por el Tribunal Constitucional Federal alemán. Finalmente, y aunque excede el ámbito estricto de la libertad religiosa subjetiva, no quisiera ignorar el modo en que se ha abordado políticamente la aproximación a la muerte al adquirir esta una significación pública. La muerte es, probablemente, un fenómeno ante el cual el posicionamiento religioso se hace inevitable de manera peculiar. La adquisición de significación pública de la muerte, por su parte, pone al descubierto de manera peculiar, igualmente, el posicionamiento político ante lo religioso, de indudable trascendencia para la justicia pública, el bienestar espiritual y, en última instancia, la misma convivencia armónica en libertad ${ }^{3}$.

Con las limitaciones que impone la brevedad exigida para este trabajo, en las páginas que siguen trataré de reflexionar sosegadamente sobre estas cuestiones. Dado que la crisis del coronavirus no está cerrada, he decidido

\footnotetext{
${ }^{1}$ Permítaseme la remisión a un vídeo que grabé respondiendo a la amable invitación del Club Tocqueville, acerca de la reconciliación con Dios y la crisis política: «Miradas sobre la crisis COVID-19»; enlace accesible desde https://unav.academia.edu/FSY/

${ }^{2}$ G. Jellinek, Die Erklärung der Menschen- und Bürgerrechte, Duncker \& Humblot, 1895.

${ }^{3}$ La trascendencia de la religión para la vida pública fue paradigmáticamente enfatizada por George Washington en su Farewell Address a la nación americana, como es conocido.
} 
acotar el alcance de este trabajo ciñéndome a lo ocurrido entre la declaración del estado de alarma y el término de las vacaciones estivales.

\section{LA LIBERTAD RELIGIOSA Y DE CULTOS}

\section{La situación en España}

El objeto de estas páginas es, sobre todo, llevar a cabo una reflexión sobre la libertad religiosa y de cultos en su "dimensión subjetiva", esto es, sobre la libertad religiosa en sentido estricto. Me ocuparé inicialmente de la situación en España, para proceder a continuación a un examen crítico de algunas de las principales resoluciones dictadas en el ámbito comparado.

\section{a) La normativa: examen crítico}

1. Desde un punto de vista normativo, es preciso aludir, ante todo, al artículo 11 del Real Decreto 463/2020, de 14 de marzo, por el que —al abrigo del artículo 116 CE - se declaró el estado de alarma: «la asistencia a los lugares de culto y a las ceremonias civiles y religiosas, incluidas las fúnebres, se condicionan a la adopción de medidas organizativas consistentes en evitar aglomeraciones de personas, en función de las dimensiones y características de los lugares, de tal manera que se garantice a los asistentes la posibilidad de respetar la distancia entre ellos de, al menos, un metro».

Como puede colegirse de este precepto, la declaración del estado de alarma no contenía, como tal, una prohibición expresa de las ceremonias religiosas, ni siquiera de las ceremonias fúnebres. No obstante, el artículo 7 del mismo Real Decreto, que regulaba la «limitación de la libertad de circulación de las personas», no incluyó entre las excepciones que permitían la libre circulación la asistencia a Misa u otros servicios religiosos. Sí incluyó, por el contrario, los siguientes:

“a) Adquisición de alimentos, productos farmacéuticos y de primera necesidad, así como adquisición de otros productos y prestación de servicios de acuerdo con lo establecido en el artículo 10.

b) Asistencia a centros, servicios y establecimientos sanitarios. 
fundación

Manuel Giménez Abad

deEstudios Parlamentarios ydelEstado Autonómico

c) Desplazamiento al lugar de trabajo para efectuar su prestación laboral, profesional o empresarial.

d) Retorno al lugar de residencia habitual.

e) Asistencia y cuidado a mayores, menores, dependientes, personas con discapacidad o personas especialmente vulnerables.

f) Desplazamiento a entidades financieras y de seguros.

g) Por causa de fuerza mayor o situación de necesidad.

h) Cualquier otra actividad de análoga naturaleza."

Por su parte, el artículo 10 del propio Real Decreto, al cual se remite el referido artículo 7.1.a, prevé la excepción de los siguientes servicios:

“1. (...) los establecimientos comerciales minoristas de alimentación, bebidas, productos y bienes de primera necesidad, establecimientos farmacéuticos, sanitarios, centros o clínicas veterinarias, ópticas y productos ortopédicos, productos higiénicos, prensa y papelería, combustible para la automoción, estancos, equipos tecnológicos y de telecomunicaciones, alimentos para animales de compañía, comercio por internet, telefónico o correspondencia, tintorerías, lavanderías y el ejercicio profesional de la actividad de peluquería a domicilio. En cualquier caso, se suspenderá la actividad de cualquier establecimiento que, a juicio de la autoridad competente, pueda suponer un riesgo de contagio por las condiciones en las que se esté desarrollando."

Una primera observación crítica debe dirigirse, a mi juicio, al lamentable limbo jurídico en que fueron abandonados los actos de culto. Por el tenor del artículo 11, la celebración de ceremonias religiosas no sólo no estaba prohibida, sino que se permitía expresamente siempre y cuando se adoptasen -como es lógico - las medidas de seguridad e higiene adecuadas. Esta autorización, sin embargo, se veía entorpecida por el mismo texto normativo, que no incluyó las ceremonias religiosas entre los servicios esenciales permitidos bajo condiciones, ni tan siquiera en los días fijados como sagrados por el calendario litúrgico. Haciendo míos los argumentos de varios jueces del Tribunal Supremo de Estados Unidos — que expondré más adelante- en los asuntos South Bay United Pentecostal Church y Calvary Chapel, considero que, mutatis mutandis, es muy posible que estemos ante una discriminación religiosa. Pese a gozar de un puesto preeminente en la tradición constitucional y ser uno de los principales derechos fundamentales recogidos por la Sección $1^{\text {a }}$ del Capítulo $2^{\circ}$ 
del Título I de la Constitución, pienso que la libertad de cultos fue tratada desconsideradamente frente a otros servicios, a mi parecer, de menor relevancia constitucional. Porque, desde una conciencia religiosa, que es la que protege la llamada dimensión "positiva" de la libertad de cultos prevista por el artículo 16 de la Constitución, ¿puede sostenerse con seriedad que es más importante el servicio de prensa, el servicio de estanco o las clínicas veterinarias, que el culto litúrgico, al menos en los días señalados como sagrados por la autoridad religiosa? Piénsese, en este sentido, en lo esencial que es para la vida de tantos cristianos el precepto dominical, máxime en el triduo sacro pascual. Obviamente, tales ceremonias no deberían permitirse en cuanto que supusiesen un peligro inasumible de contagio, no tanto para proteger la salud de quienes están dispuestos a arriesgarla participando en ellas, cuanto por razones de salud pública. Me cuesta creer, con todo, que no sea posible admitirlas sujetándolas a severas medidas, análogamente a como ha ocurrido con otros servicios, en algunos casos, menos esenciales ${ }^{4}$.

2. Merece un comentario específico la Orden SND/298/2020, de 29 de marzo, por la que se establecieron medidas excepcionales en relación con los velatorios y ceremonias fúnebres para limitar la propagación y el contagio por la covid-19. Dictada por el Ministro de Sanidad de acuerdo con las competencias que le atribuía el Real decreto $463 / 2020^{5}$, la norma prohibía «los velatorios en

${ }^{4}$ Incidentalmente, quisiera elogiar la actitud del obispo de Alcalá de Henares. Mons. Reig Pla, llamando la atención sobre la no inclusión de la asistencia religiosa entre los servicios esenciales. Además, acogiéndose a una interpretación de la normativa favorable a la libertad religiosa amparada por la Constitución, mantuvo en su diócesis las celebraciones litúrgicas, no sin imponer escrupulosas medidas sanitarias como la reducción de aforo, desinfección de bancos, limpieza de suelos y de vasos sagrados, etc.

${ }^{5}$ «Artículo 4 Real Decreto 463/2020, de 14 de marzo:

(...) 2. Para el ejercicio de las funciones a que se hace referencia en este real decreto, bajo la superior dirección del Presidente del Gobierno, serán autoridades competentes delegadas, en sus respectivas áreas de responsabilidad:

a) La Ministra de Defensa.

b) El Ministro del Interior.

c) El Ministro de Transportes, Movilidad y Agenda Urbana.

d) El Ministro de Sanidad.

3. Los Ministros designados como autoridades competentes delegadas en este real decreto quedan habilitados para dictar las órdenes, resoluciones, disposiciones e instrucciones interpretativas que, en la esfera específica de su actuación, sean necesarios para garantizar la prestación de todos los servicios, ordinarios o extraordinarios, en orden a la protección de personas, bienes y lugares, mediante la adopción de cualquiera de las medidas previstas en el artículo once de la Ley Orgánica 4/1981, de 1 de junio.

Los actos, disposiciones y medidas a que se refiere el párrafo anterior podrán adoptarse de oficio o a solicitud motivada de las autoridades autonómicas y locales competentes, de acuerdo 
todo tipo de instalaciones, públicas o privadas, así como en los domicilios particulares» (art. 3), y posponía «la celebración de cultos religiosos o ceremonias civiles fúnebres hasta la finalización del estado de alarma». Admitía, de todos modos, una ceremonia de «enterramiento o despedida para la cremación de la persona fallecida», restringiendo la participación en la misma «a un máximo de tres familiares o allegados, además, en su caso, del ministro de culto o persona asimilada de la confesión respectiva para la práctica de los ritos funerarios de despedida del difunto", y exigiendo el respeto de «la distancia de uno a dos metros entre ellos» (art. 5).

Se me hace difícil, francamente, emitir un juicio seguro acerca de la proporcionalidad de esta medida. Si la ausencia de los actos de culto del catálogo de servicios esenciales o necesarios me suscita rechazo, por cuanto parece traslucir un marco social y jurídico insensible a las necesidades espirituales y religiosas, la restricción de los servicios fúnebres, tan profundamente humanos, acaso estuvo justificada por los riesgos que para la salud comporta el contacto con personas fallecidas a causa del virus. En todo caso, también aquí se puede haber pasado por alto la importancia humana de ese último ritual de despedida y oración por los difuntos, y se echa en falta la creatividad regulatoria que existe para asegurar la prestación aséptica de otros servicios. Tampoco en esto puede decirse que la dimensión religiosa y trascendente del hombre haya sido privilegiada frente a otras urgencias materiales. Al contrario, lo radical de la limitación, que no hace ningún género de distingos entre tipos de fallecidos, y que reduce la presencia de familiares a un número exiguo, merece también, a mi juicio, cuando menos una reflexión.

3. En fin, quisiera referirme también a las sucesivas órdenes dictadas para regular la transición hacia lo que ha venido a denominarse como «nueva normalidad».

a) En primer lugar, es preciso aludir a la flexibilización llevada a cabo por la Orden SND/399/2020, de 9 de mayo, que regulaba la llamada «fase 1 » del plan de transición señalado. En apretada síntesis, el artículo 8 de esta Orden relajaba las condiciones de celebración de velatorios y enterramientos ${ }^{6}$, y su

con la legislación aplicable en cada caso y deberán prestar atención a las personas vulnerables. Para ello, no será precisa la tramitación de procedimiento administrativo alguno». ${ }^{6}$ Artículo 8 Orden SND/399/2020, de 9 de mayo: 
artículo 9 permitía el culto público, el cual quedaba sometido a un profuso catálogo de restricciones higiénicas que seguiría vigente a lo largo de todo el proceso de desescalada:

"1. Se permitirá la asistencia a lugares de culto siempre que no se supere un tercio de su aforo y que se cumplan las medidas generales de seguridad e higiene establecidas por las autoridades sanitarias.

2. Si el aforo máximo no estuviera claramente determinado se podrán utilizar los siguientes estándares para su cálculo:

a) Espacios con asientos individuales: una persona por asiento, debiendo respetarse, en todo caso, la distancia mínima de un metro.

b) Espacios con bancos: una persona por cada metro lineal de banco.

c) Espacios sin asientos: una persona por metro cuadrado de superficie reservada para los asistentes.

d) Para dicho cómputo se tendrá en cuenta el espacio reservado para los asistentes excluyendo pasillos, vestíbulos, lugar de la presidencia y colaterales, patios y, si los hubiera, sanitarios.

Determinado el tercio del aforo disponible, se mantendrá la distancia de seguridad de, al menos, un metro entre las personas. El aforo máximo deberá publicarse en lugar visible del espacio destinado al culto.

No se podrá utilizar el exterior de los edificios ni la vía pública para la celebración de actos de culto.

3. Sin perjuicio de las recomendaciones de cada confesión en las que se tengan en cuentan las condiciones del ejercicio del culto propias de cada una de ellas, con carácter general se deberán observar las siguientes recomendaciones:

a) Uso de mascarilla con carácter general.

b) Antes de cada reunión o celebración, se deberán realizar tareas de desinfección de los espacios utilizados o que se vayan a utilizar, y

1. Los velatorios podrán realizarse en todo tipo de instalaciones, públicas o privadas, con un límite máximo en cada momento de quince personas en espacios al aire libre o diez personas en espacios cerrados, sean o no convivientes.

2. La participación en la comitiva para el enterramiento o despedida para cremación de la persona fallecida se restringe a un máximo de quince personas, entre familiares y allegados, además de, en su caso, el ministro de culto o persona asimilada de la confesión respectiva para la práctica de los ritos funerarios de despedida del difunto.

3. En todo caso, deberán respetarse las medidas de seguridad e higiene establecidas por las autoridades sanitarias para la prevención del COVID-19, relativas al mantenimiento de una distancia mínima de seguridad de dos metros, higiene de manos y etiqueta respiratoria. 
durante el desarrollo de las actividades, se reiterará la desinfección de los objetos que se tocan con mayor frecuencia.

c) Se organizarán las entradas y salidas para evitar agrupaciones de personas en los accesos e inmediaciones de los lugares de culto.

d) Se pondrá a disposición del público dispensadores de geles hidroalcohólicos o desinfectantes con actividad virucida autorizados y registrados por el Ministerio de Sanidad, en todo caso en la entrada del lugar de culto, que deberán estar siempre en condiciones de uso.

e) No se permitirá el uso de agua bendecida y las abluciones rituales deberán realizarse en casa.

f) Se facilitará en el interior de los lugares de culto la distribución de los asistentes, señalizando si fuese necesario los asientos o zonas utilizables en función del aforo permitido en cada momento.

g) En los casos en los que los asistentes se sitúen directamente en el suelo y se descalcen antes de entrar en el lugar de culto, se usarán alfombras personales y se ubicará el calzado en los lugares estipulados, embolsado y separado.

h) Se limitará al menor tiempo posible la duración de los encuentros o celebraciones.

i) Durante el desarrollo de las reuniones o celebraciones, se evitará:

1. El contacto personal, manteniendo en todo momento la distancia de seguridad.

2.․ - La distribución de cualquier tipo de objeto, libros o folletos.

3. Tocar o besar objetos de devoción u otros objetos que habitualmente se manejen.

4.ㄴ La actuación de coros."

También en este punto, es difícil emitir un veredicto cierto sobre la proporcionalidad de la mayoría de las restricciones impuestas, sin perjuicio de que hay dos incisos que, en su generalidad, me suscitan algunas dudas. Me refiero a la prohibición genérica de «utilizar el exterior de los edificios» y «la vía pública para la celebración de actos de culto» (letra d) que, aunque sea comprensible para evitar concentraciones sociales inasumibles durante una fase crítica de la pandemia ${ }^{7}-$ p. ej., las procesiones de Semana Santa-,

\footnotetext{
${ }^{7}$ Frente a una solicitud de suspensión cautelar, la Sección $4^{a}$ del Tribunal Supremo dictó Auto
} desestimatorio el día 10 de junio (ATS 3523/2020). Pienso que, con buen criterio, el Tribunal 
redactada de modo tan amplio puede dar lugar a prácticas policiales abusivas; y a la previsión de limitar "al menor tiempo posible la duración de los encuentros o celebraciones» (letra h). Esta última limitación no pasa de ser una admonición difícilmente controlable, impuesta además sobre una actividad —la adoración litúrgica - que exige, por definición, sosiego y calma.

b) Una flexibilización ulterior se llevó a cabo, para la llamada «fase 2» de la desescalada, por la Orden SND/414/2020, de 16 de mayo. Básicamente, esta Orden aumentaba el aforo permitido para los velatorios y enterramientos (art. 8) y para todo tipo de actos de culto (art. 9). En este segundo caso, se pasaba de un aforo permitido de un tercio a la mitad, y se mantenían las distancias de seguridad. La lista de condiciones higiénicas y sanitarias prevista para la «fase 1 » por los arts. 9.2 y 9.3 de la Orden SND 399/2020 permanecía invariable, por lo que cabe reproducir la sucinta crítica vertida sobre aquella.

El artículo 10.1 de la Orden SND/414/2020 añadía una previsión específica para las ceremonias nupciales, admitidas «en todo tipo de instalaciones, públicas y privadas, ya sea en espacios al aire libre o espacios cerrados", siempre que no se superase «el cincuenta por ciento de su aforo, y en todo caso un máximo de cien personas en espacios al aire libre o de cincuenta personas en espacios cerrados", y siempre y cuando se cumpliesen las demás medidas de seguridad e higiene requeridas. A este respecto, únicamente procede poner en cuestión el hecho de ceñir la habilitación expresa del culto en espacios libres a las ceremonias nupciales y no extenderla a otro tipo de ceremonias - ni siquiera, como se ha indicado, a las señaladas como precepto sagrado- sujetas, eso siempre, a medidas de seguridad 0 incluso a autorización expresa de las autoridades.

Por último, el artículo 35.2 de la Orden establecía indicaciones concretas para ordenar la circulación en lugares religiosos.

c) La última medida de flexibilización que procede comentar aquí es la Orden SND/458/2020, de 30 de mayo, prevista para la llamada «fase 3 del Plan para

Supremo advirtió que, «de adoptarse la medida pretendida, quedarían sin regulación o prevención alguna una serie de situaciones, como son las de culto religioso en las vías públicas, que originan concentraciones sociales, en las que los riesgos de contagio son sobradamente conocidos» (FJ 3). En efecto, la simple suspensión del inciso habría producido un vacío indeseable, lo que no quiere decir, de todos modos, que la genérica prohibición contenida en él fuera proporcionada. 
la transición hacia una nueva normalidad». Nuevamente, se ampliaba el número posible de asistentes a los velatorios, enterramientos y ceremonias fúnebres, con las mismas exigencias de respeto de la «distancia mínima de seguridad de dos metros, higiene de manos y etiqueta respiratoria» (art. 8.3). E aforo previsto, con carácter general, para los actos de culto, ascendía al setenta y cinco por ciento de la capacidad de los templos, y el catálogo exhaustivo de restricciones de la «fase 1 » conservaba su vigencia.

\section{b) Atentados contra la libertad religiosa: episodios concretos}

Junto con la alusión a la normativa, es oportuna la referencia de algunos episodios de discriminación religiosa o de agresión a la libertad religiosa que se han producido durante el tiempo de confinamiento:

1. Por su gravedad especial, deben referirse las interrupciones de celebraciones litúrgicas sagradas por parte de la policía. Ya se ha dicho que, aun abandonadas a una cierta desprotección por el Gobierno, estas se encontraban expresamente permitidas siempre y cuando cumpliesen con las medidas sanitarias. Pues bien, fueron los propios agentes del orden quienes, en algunos casos, violaron la libertad religiosa y transgredieron la legislación del estado de alarma. Así ocurrió, por ejemplo, durante la celebración de la Pasión del Señor en la catedral de Granada, el día 10 de abril ${ }^{8}$. Policías nacionales irrumpieron en una catedral con menos de veinte feligreses y amenazaron con imponerles sanciones si no abandonaban el templo. Pacíficamente, el obispo interrumpió la celebración, instó a la obediencia y continuó la ceremonia con la catedral vacía.

Episodios semejantes se han registrado en otros lugares ${ }^{9}$. En algunos de estos casos, se han abierto diligencias para verificar si se cumplen las condiciones

${ }^{8}$ Cfr., p. ej., V. Torre de Silva, «¿El Covid-19 ataca también a la libertad religiosa?», Diario ABC, 29 de abril de 2020; y Granada Hoy: «La Policía desaloja la Catedral de Granada durante la misa del arzobispo por el estado de alarma», 10 de abril de 2020.

${ }^{9}$ Así, por ejemplo, el 13 de abril fue desalojada la parroquia de San Juan y San Pablo, de San Fernando de Henares, donde estaban celebrando la Misa el párroco y cinco personas. Un día antes, en la parroquia de San Jenaro de Madrid, la policía local impidió a un sacerdote decir la Misa del Domingo de Resurrección, que iba dirigida a los balcones de la vecindad, donde habían salido varios vecinos para oírla. Cfr., p. ej., Torre de Silva, «¿El Covid-19 ataca también a la libertad religiosa?», Diario $A B C$, cit., y Noticias para municipios: «Abren diligencias por el desalojo de 6 personas que celebraban una misa», 18 de mayo de 2020. 
del tipo previsto en el artículo 523 del Código Penal: «el que con violencia, amenaza, tumulto o vías de hecho, impidiere, interrumpiere o perturbare los actos, funciones, ceremonias o manifestaciones de las confesiones religiosas inscritas en el correspondiente registro público del Ministerio de Justicia e Interior, será castigado con la pena de prisión de seis meses a seis años, si el hecho se ha cometido en lugar destinado al culto, y con la de multa de cuatro a diez meses si se realiza en cualquier otro lugar».

2. Un episodio digno de mencionarse fue el enfrentamiento entre el Cardenal Omella, Presidente de la Conferencia Episcopal Española, y el Presidente de la Generalitat, Quim Torra, a causa de la restricción del aforo para el funeral por las víctimas del coronavirus a diez personas ${ }^{10}$. El día 27 de junio, el Cardenal Omella anunció acciones legales contra la Generalitat por una prohibición «discriminatoria e injusta» y, al día siguiente, Torra abrió un expediente sancionador contra el arzobispado por incumplir la limitación impuesta.

\section{Observaciones sobre el Derecho comparado}

Las controversias sobre el alcance de las restricciones a la libertad religiosa y, muy en particular, las discriminaciones del culto frente a otro tipo de actividades de menor relevancia se han dado no sólo en España, sino también en otros países occidentales. Para no extender en exceso la exposición, en este epígrafe nos centraremos en la situación en Estados Unidos y Alemania.

\section{a. El Tribunal Supremo de Estados Unidos}

1. En Estados Unidos, el primer caso en que se estudió la afectación de las restricciones originadas por el coronavirus a la libertad religiosa fue el asunto South Bay United Pentecostal Church et al. v. Gavin Newsom, Governor of California, et al., de 29 de mayo de 2020. En el origen de este caso se encontraba la solicitud de South Bay United Pentecostal Church de tutela judicial cautelar frente a una orden ejecutiva del Gobernador de California. A fin de evitar la expansión del coronavirus, dicha orden restringía la participación en actos de culto al $25 \%$ del aforo de los edificios, o a un máximo de cien asistentes. Deseosos de celebrar solemnemente la Fiesta de Pentecostés, los

${ }^{10}$ Cfr. «Torra contra Omella», en Religión Confidencial, de 30 de julio de 2020. 
recurrentes ponían en tela de juicio unas exigencias legales que no se habían impuesto a negocios similares, y solicitaron sin éxito su suspensión, sucesivamente, ante la Corte del Distrito y ante la Corte de Apelaciones del Noveno Circuito. Tras esta última desestimación de su solicitud, aprobada por dos votos contra uno, los demandantes apelaron ante el Tribunal Supremo de los Estados Unidos, el cual rechazó sus pretensiones.

a) La argumentación favorable a la desestimación la encontramos en el voto concurrente del Chief Justice, John Roberts. Sus consideraciones generales se encuentran, a mi juicio, cargadas de razonabilidad, si bien no me parece del todo claro que lleguen a tocar el punctum dolens de la orden ejecutiva, a saber, la discriminación religiosa. En palabras de Roberts, «la cuestión precisa acerca de cuándo las restricciones sobre actividades sociales particulares deberían levantarse durante la pandemia constituye un asunto dinámico e intensamente dependiente de hechos (fact-intensive matter), sujeto al desacuerdo razonable ${ }^{11}$. Siendo misión constitucional de las autoridades públicas proteger la salud y la seguridad de la población, lo cierto es que "cuando tales autoridades actúan en áreas cargadas de incertidumbres médicas y científicas, su libertad tiene que ser especialmente amplia» ${ }^{12}$. Toda vez que no sobrepasan generosos márgenes, sus estimaciones no deberían ser sometidas «a cuestionamiento por un 'poder judicial federal no elegido' que carece del trasfondo, competencia y pericia para valorar la salud pública, y que no es responsable frente a la población ${ }^{13}$.

b) Como ya he señalado, los argumentos vertidos por Roberts son, con carácter general, acertados, y justifican convenientemente la actitud de deferencia que debe adoptarse frente a decisiones que dependen de un conocimiento muchas veces ajeno al juez. Dicho esto, hay un punto en el que pienso que la valoración es factible, realista y aun obligada, a saber, el de la discriminación. En ello se centra la opinión disidente del Juez Kavanaugh, a la que se adhieren los Jueces Thomas y Gorsuch. Al decir del voto disidente, el "problema constitucional básico» es que la orden restringe la capacidad de asistencia a servicios religiosos al $25 \%$ de la capacidad de los edificios o a 100

11 Opinión concurrente del Chief Justice John Roberts, en South Bay United Pentecostal Church et al. v. Gavin Newsom, Governor of California, et al., de 29 de mayo de 2020, p. 2.

${ }^{12} \mathrm{lbid}$.

${ }^{13} \mathrm{lbid}$. 
participantes, y no hace lo propio con negocios seculares comparables como «fábricas, oficinas, supermercados, restaurantes, tiendas, farmacias, centros comerciales (shopping malls), tiendas de mascotas, librerías, floristerías, peluquerías y dispensarios de cannabis ${ }^{14}$. En el voto, se alude a numerosas opciones que podía haber seguido el Estado — como de hecho hizo con otros negocios - para preservar la seguridad sin discriminar. «El Estado posee también un margen substancial para determinar las líneas, en especial ante una emergencia. Pero lo relevante aquí es que la Constitución impone una restricción clave a la hora de trazar las líneas: el Estado no puede discriminar contra la religión» ${ }^{15}$. Concluye el voto que «la restricción de ocupación a un tope del $25 \%$ en los servicios religiosos discrimina indiscutiblemente frente a la religión, y tal discriminación viola la Primera Enmienda».

2. Más grave que el caso aludido fue el asunto resuelto en Calvary Chapel Dyaton Valley v. Steve Sisolak, Governor of Nevada, et al., de 24 de julio de 2020. En esta ocasión, los recurrentes habían solicitado una orden de suspensión de una directiva del Gobernador de Nevada, dictada el 28 de mayo de 2020, que prohibía la asistencia a servicios religiosos a más de cincuenta personas y, al mismo tiempo, permitía que servicios seculares como destilerías, gimnasios y — lo más asombroso- casinos, aceptasen un $50 \%$ de su aforo. En el caso de los enormes casinos de Las Vegas, esto suponía la posibilidad de acoger a miles de personas.

A los cerca de cuatro meses de vigencia de la directiva, y después de fracasar la solicitud de tutela urgente de Calvary Chapel ante la Corte Federal del Distrito y ante la Corte de Apelaciones del Noveno Circuito, el Tribunal Supremo rechazó igualmente su petición con una escueta orden de apenas una frase: «la solicitud de un mandato judicial presentada a la Juez Kagan y referida por ella a la Corte es denegada». Tampoco contamos aquí, pues, con la argumentación que llevó a la mayoría del Alto Tribunal a desestimar las pretensiones de los recurrentes, y ni siquiera disponemos de un voto concurrente que diese alguna razón -como ocurría con la opinión de Roberts en South Bay United Pentecostal Church-. Sí gozamos, empero, de las

\footnotetext{
${ }^{14}$ Opinión concurrente del Juez Brett Cavanaugh, en South Bay United Pentecostal Church et al. v. Gavin Newsom, Governor of California, et al., de 29 de mayo de 2020, p. 1.

${ }^{15}$ Ibid., p. 3.
} 
contundentes opiniones discrepantes de los jueces Alito - a quien se adhieren Kavanaugh y Thomas-, Gorsuch y el propio Kavanaugh.

a) El juez Samuel Alito subrayó que «la Constitución garantiza el libre ejercicio de la religión», mientras que «no dice nada sobre la libertad de jugar» a las cartas, máquinas de la suerte ni otros juegos de azar. En este sentido, «el hecho de que Nevada discrimine a favor de la poderosa industria del juego y sus empleados no tiene por qué sorprender, pero la disposición de este Tribunal a permitir semejante discriminación resulta decepcionante» ${ }^{16}$. Enfatizaba Alito, igualmente, la inclinación de Calvary Chapel -y, con carácter general, de los templos dedicados al culto- de adoptar y cumplir severas medidas de protección - distancia de seguridad, uso de mascarillas salvo brevísimos instantes como la sagrada comunión, etc.-, así como el mayor riesgo que suponía la apertura de muchos de los negocios seculares a los que se permitía un aforo altamente superior. En los casinos, por ejemplo, las actividades llevadas a cabo entrañan una estrecha aproximación física y una notable falta de seguridad -remoción de mascarillas durante la consumición, desinhibición por ingesta de alcohol, etcétera-. Se trata, sin lugar a duda, de un riesgo mucho mayor que el de las sobrias ceremonias celebradas en una iglesia. «La idea de que permitir a Calvary Chapel la admisión de 90 adoradores constituye un riesgo mayor para la salud pública que permitir a los casinos operar al $50 \%$ es difícil de digerir » ${ }^{17}$, concluía en este punto Alito.

Otro aspecto que subrayaba acertadamente Alito era el tiempo transcurrido desde el inicio de la crisis. Al comienzo de la pandemia, las restricciones sin precedentes de la libertad, que incluían la afectación de la libertad religiosa, se justificaban en parte porque «las autoridades públicas tienen que responder con rapidez y determinación frente a circunstancias fluctuantes e inciertas». En situaciones de emergencia, es posible que las autoridades «no sean capaces de elaborar reglas diseñadas con precisión ${ }^{18}$. No era este el caso de Nevada, ya que la directiva del Gobernador había sido dictada nada menos que el 28 de mayo, más de dos meses después de la declaración del estado de emergencia, el 12 de marzo. Al tiempo de la resolución del Alto Tribunal, habían pasado

\footnotetext{
${ }^{16}$ Opinión disidente del Juez Samuel Alito, en Calvary Chapel Dyaton Valley v. Steve Sisolak, Governor of Nevada, et al., de 24 de julio de 2020, p. 1.

${ }^{17}$ Ibid., p. 6.

${ }^{18} \mathrm{Ibid} ., \mathrm{p} .3$.
} 
nada menos que cuatro meses y la norma invasiva de la libertad religiosa seguía vigente.

b) La opinión disidente de Gorsuch apenas requiere comentario y, por su claridad y concisión, bien puede reproducirse en su integridad:

«Este es un caso sencillo. De acuerdo con el edicto del Gobernador, un cine 10-screen 'múltiplex' puede alojar a 500 espectadores en cualquier momento. Un casino, igualmente, puede acoger a cientos a la vez, con tal vez seis personas apiñadas en la mesa de dados y un número similar reunidas alrededor de cada ruleta. Grandes números y espacios cerrados están bien en esos lugares. Pero las iglesias, sinagogas y mezquitas tienen prohibido admitir a más de cincuenta adoradores — sin importar cuán grande sea el edificio, cuántos lleven mascarilla, sin importar en absoluto las precauciones-. En Nevada, según parece, es mejor estar en el ocio que en la religión. Tal vez no sea nada nuevo. Pero la Primera Enmienda prohíbe semejante obvia discriminación frente al ejercicio de la religión. El mundo que hoy habitamos, con una pandemia sobre nosotros, plantea desafíos inusuales. Pero no hay mundo en el cual la Constitución permita a Nevada favorecer a Caesars Palace sobre Calvary Chapel» ${ }^{19}$.

c) Lo más interesante, a mi modo de ver, del voto disidente del Juez Kavanaugh, era la comparación que establecía entre este caso y el otro resuelto por el Tribunal Supremo, arriba comentado. En South Bay United Pentecostal Church, «California trató a las organizaciones religiosas mejor que a algunas organizaciones seculares como los cines, pero peor que a otras organizaciones seculares como restaurantes, supermercados, tiendas, farmacias, peluquerías, oficinas, fábricas y similares» ${ }^{20}$. El Juez disidente admitía, además, que «el Chief Justice había enfatizado adecuadamente el elevado estándar requerido para obtener la tutela cautelar en este Tribunal, así como la constante y rápidamente cambiante emergencia para la salud pública» ${ }^{21}$. Con todo, el Juez Kavanaugh se resistía a otorgar -como parecía

\footnotetext{
${ }^{19}$ Opinión disidente del Juez Neil Gorsuch, en Calvary Chapel Dyaton Valley v. Steve Sisolak, Governor of Nevada, et al., de 24 de julio de 2020.

${ }^{20}$ Opinión disidente del Juez Brett Kavanaugh, en Calvary Chapel Dyaton Valley v. Steve Sisolak, Governor of Nevada, et al., de 24 de julio de 2020, p. 11.

${ }^{21}$ Ibid.
} 
hacer Roberts - que los restaurantes y supermercados permitidos en el caso South Bay comportasen riesgos inferiores a las iglesias. Sea como fuere, concluía que, incluso «aceptando South Bay como precedente, este asunto es muy diferente, ya que implica a bares, casinos y gimnasios. La distinción sanitaria de Nevada, basada en la covid-19, entre (i) bares, casinos y gimnasios, de un lado; y (ii) servicios religiosos, de otro; desafía el sentido común» ${ }^{22}$. De hecho, «el Estado no puede sostener plausiblemente que esos grandes negocios seculares resulten categóricamente más seguros que los servicios religiosos, o que sólo los servicios religiosos -y no los bares, casinos y gimnasios - impliquen a personas congregadas en grupos amplios 0 manteniendo una proximidad estrecha por períodos extensos de tiempo ${ }^{23}$.

Llegados a este punto, pienso que no está fuera de lugar emitir sosegadamente un juicio muy negativo sobre el hecho de que el Tribunal Supremo de los Estados Unidos —el frontispicio de cuya noble sede luce la enseña: «Equal Justice under Law»- tolere que, en nombre de la salud pública, se prohíba durante meses que más de cincuenta personas se reúnan en un templo para adorar a Dios, a la vez que se permite que los casinos de Las Vegas abran sus puertas al 50\% de su aforo. ¿Cómo no detectar un desenfoque en el mismo planteamiento de la libertad que merece protección?

\section{b. El Tribunal Constitucional Federal alemán}

A continuación, me referiré a las decisiones del Tribunal Constitucional Federal de Alemania sobre las medidas adoptadas para hacer frente al coronavirus que afectan a la libertad religiosa, reconocida por el artículo 4 de la Ley Fundamental de Bonn ${ }^{24}$.

${ }^{22}$ Ibid.

${ }^{23}$ Ibid, pp. 11-12.

${ }^{24}$ Es oportuno indicar que, en Alemania, algunas de las principales medidas para frenar la expansión del coronavirus fueron adoptadas inicialmente por los Länder de manera coordinada, al amparo del $\S 32$ de la Ley para la prevención y la lucha frente a enfermedades infecciosas en seres humanos (Gesetz zur Verhütung und Bekämpfung von Infektionskrankheiten beim Menschen: Infektionsschutzgesetz). 
1. La primera decisión a la que ha de hacerse referencia ${ }^{25}$ forma parte de un conjunto más amplio de resoluciones aprobadas por el Tribunal Constitucional Federal el 10 de abril de 2020, en las que se estudiaba la denegación de medidas cautelares frente a normas destinadas a hacer frente al coronavirus. En la resolución comentada aquí se resolvía la solicitud de una disposición cautelar (einstweilige Anordnung) que suspendiese un decreto del Gobierno del Land de Hesse. Aprobado el 17 de marzo, el decreto prohibía temporalmente, hasta el 19 de abril, las reuniones en iglesias, mezquitas y sinagogas, así como las reuniones de otras confesiones religiosas. El recurrente había impugnado infructuosamente la norma mencionada ante el Tribunal Administrativo de Hesse, y su demanda iba acompañada de una solicitud de suspensión cautelar del precepto controvertido. Ante la desestimación de sus pretensiones mediante resolución de 7 de abril, elevó recurso al Tribunal Constitucional Federal $^{26}$, que desestimó igualmente la medida cautelar solicitada.

a) Es conveniente dejar sentado, en primer lugar, que el Tribunal rehusó explícitamente prejuzgar el fondo del asunto, algo que, de acuerdo con su propia jurisprudencia, tan sólo procedería en caso de que la demanda fuese manifiestamente infundada. Descartado esto, el asunto podría llegar a plantearse en el futuro en un recurso individual de tutela de los derechos fundamentales (Verfassungsbeschwerde). La desestimación de la solicitud se debe, en realidad, a una ponderación de los riesgos derivados de dictar o no la suspensión cautelar del decreto. En este sentido, el Tribunal pondera las consecuencias que, para los derechos fundamentales -en este caso, para la libertad religiosa - se desprenderían de no conceder la tutela cautelar en caso de que los derechos hubiesen sido violados con los perjuicios que,

\footnotetext{
${ }^{25}$ Resolución de la Segunda Cámara del Primer Senado del TCF, de 10 de abril de 2020 (1 $B v Q 28 / 2020$ ), relativa a la solicitud de suspensión cautelar del $\S 1$, párrafo 5 , del Cuarto Decreto del Gobierno del Land de Hesse, de 17 de marzo de 2020, para la lucha contra el coronavirus, en la versión resultante de la modificación llevada a cabo por el artículo 4 del Decreto de adaptación de las resoluciones para la lucha contra el coronavirus, de 20 de marzo de 2020.

${ }^{26}$ Art. § 32 (1) LTCF: «En un litigio, el Tribunal Constitucional podrá regular provisionalmente una situación mediante una disposición cautelar, si ello fuere de urgente necesidad para prevenir perjuicios graves, para evitar violencia inminente o por otra razón importante relativa al bien común».
} 
inversamente, se desprenderían en caso de otorgar la tutela provisional en el hipotético caso de que no se declarase la vulneración ${ }^{27}$.

b) En su argumentación, el Tribunal admite que estamos ante una «injerencia grave» (schwerwiegende Eingriff) en el derecho fundamental a la libertad religiosa. Asistente regular a la Santa Misa, el recurrente se había visto impedido, como subraya el Tribunal, de participar en la Eucaristía, una parte central de la fe católica. La injerencia vendría agravada por afectar la prohibición a la celebración de las fiestas pascuales, que constituyen el momento culminante del calendario litúrgico cristiano. En caso de prosperar su recurso, por consiguiente, se habría producido una grave violación de su derecho fundamental a la libertad religiosa ${ }^{28}$.

c) En caso contrario, sin embargo, el haber dejado sin vigor la normativa del Land podría tener graves consecuencias para la integridad física y para la vida de numerosas personas, algo que el Tribunal Administrativo de Hesse había apoyado remitiéndose a informes del Instituto Robert Koch. El Tribunal advierte explícitamente $^{29}$, además, que el artículo 2, párr. 2, de la Constitución impone también un deber de protección iusfundamental (grundrechtliche Schutzpflicht) de la vida y la integridad física.

d) El Alto Tribunal tiene en cuenta otros factores como la temporalidad de la norma, que obligaría a una revisión de los desarrollos de la pandemia, y señala que las medidas han de someterse a un «control continuo de proporcionalidad» (fortlaufende Prüfung der Verhältnißmäßigkeit) de carácter estricto. Con todo, la prohibición resulta avalada con base en la aludida ponderación de riesgos.

e) Aunque sea un caso muy similar, valga una referencia sucinta a otra decisión dictada el mismo día por el Alto Tribunal, en la que se dictaminaba acerca de una normativa prácticamente igual aprobada en Berlín ${ }^{30}$. Lo específico de este segundo caso era que uno de los recurrentes había propuesto medidas específicas de seguridad, verbigracia, un aforo máximo de

${ }^{27}$ Resolución 1 BvQ 28/2020, de 10 de abril de 2020, §§ 8-10 (2/5 y 3/5), así como la jurisprudencia allí citada.

${ }_{28}$ Ibid., § 11 (p. 3/5).

29 Ibid., § 14 (p. 4/5).

${ }^{30}$ Resolución de la Segunda Cámara del Primer Senado del TCF (1 BvQ 31/2020), relativa al Decreto de medidas de contención del SARS-CoV-2 aprobado por el Senado de Berlín, según su versión de 22 de marzo de 2020. Al igual que el decreto de Hesse, la fecha de expiración del decreto de Berlín era el 19 de abril. 
cincuenta personas, control de accesos al templo y una distancia de seguridad de un metro y medio. A juicio del Alto Tribunal, sin embargo, las medidas propuestas no serían lo suficientemente seguras como para merecer dejar sin efecto la normativa impugnada.

2. Para terminar de describir la posición del Tribunal Constitucional Federal alemán en relación con el coronavirus, es preciso añadir una referencia a una resolución de 29 de abril de 2020 (1 BvQ 44/20). El recurrente era una asociación musulmana que había solicitado la suspensión cautelar de la normativa de Baja Sajonia que prohibía las reuniones para el culto durante los días 23 de abril a 23 de mayo de $2020^{31}$. Concretamente, la asociación solicitaba que se permitiese a sus miembros celebrar la oración del viernes en su mezquita durante el mes del Ramadán, siempre cumpliendo una serie de medidas de seguridad previstas en el propio decreto para otras actividades reducción de aforo, distancia de seguridad de 1,5 metros, etc- Tras desestimar el Tribunal Superior Administrativo de Baja Sajonia sus pretensiones mediante resolución de 23 de abril de 2020, acudieron al Tribunal Constitucional, que dictó resolución estimatoria el 29 de abril.

El Tribunal Superior Administrativo de Baja Sajonia había rechazado el argumento de que las mezquitas comportasen los mismos riesgos que otros negocios permitidos bajo medidas de seguridad por el Land. A su juicio, algunas peculiaridades de los servicios religiosos, en particular su duración, simultaneidad en la oración, cánticos comunitarios y -en casos como el Ramadán- posibilidad de congregaciones numerosas, comportaban un incremento sensible de los riesgos. Por esta razón, sostenía que, desde el punto de vista de la seguridad, las reuniones en espacios religiosos mezquitas, iglesias y sinagogas- estarían más próximas a los conciertos, eventos deportivos y actividades de tiempo libre — prohibidas o severamente restringidas-que a los espacios comerciales ${ }^{32}$.

El Tribunal Constitucional Federal, por su parte, después de reiterar los aspectos específicos - ya referidos en el epígrafe anterior- de la tutela

${ }^{31}$ Concretamente, la prohibición del § 1 (5), n. 3, del Decreto para la protección frente a nuevas infecciones con el coronavirus, de 17 abril de 2020, según la versión modificada de 24 de abril de 2020: «Están prohibidas (...) las reuniones en iglesias, mezquitas, sinagogas, y las reuniones de otras comunidades religiosas...».

${ }^{32}$ Resolución de la Segunda Cámara del Primer Senado del TCF de 29 de abril de 2020 (1 $B v Q 44 / 20)$, $\S 11$ (p. 5/9 y 6/9). 
cautelar, rechaza que los argumentos del tribunal a quo puedan aplicarse al caso que se plantea. Subraya que sólo podrían darse por válidos si lo solicitado fuese una equiparación plena de "todas" las mezquitas con los espacios comerciales, lo cual no es el caso. De lo que se trataría aquí es de juzgar si, de acuerdo con el estadio de evolución de la pandemia a finales de abril, sería obligatorio admitir "excepciones" para los servicios religiosos con medidas de seguridad adecuadas, valoradas individualizadamente. Considerando la gravedad de la injerencia en el derecho fundamental a la libertad religiosa que supone impedir el culto, la respuesta del Alto Tribunal es que sí: «en atención a la grave injerencia en la libertad religiosa (...), en la actual situación de peligro y de la estrategia para combatir el riesgo epidemiológico, resulta difícilmente sostenible que el decreto no abra ninguna posibilidad a una autorización excepcional de semejantes actos de culto para casos particulares en los que, realizada una valoración comprehensiva de las circunstancias concretas eventualmente, bajo consulta a las autoridades sanitarias competentes-, pueda desecharse un incremento previsible relevante del riesgo de infección. No se entiende que semejante estimación positiva, referida al caso concreto, no pueda prosperar en ningún caso» ${ }^{33}$. El Tribunal, en fin, se preocupa de recalcar que «el objeto de la presente resolución es exclusivamente el interrogante acerca de una autorización cautelar de carácter excepcional de actos de culto religioso, sobre la base de las circunstancias concretas específicamente expuestas y discutidas al efecto en el procedimiento judicial ${ }^{34}$.

Resulta difícil, a mi modo de ver, emitir un juicio seguro sobre las resoluciones dictadas en Alemania. Dada la dependencia de los hechos de consideraciones científicas que se sustraen al simple sentido común, el riesgo de sustituir una valoración experta por la propia impresión está siempre presente. A la vez, sin embargo, la posibilidad de escudarse en la técnica para eludir la responsabilidad que a uno compete exige que la confianza en la decisión de la autoridad no sea del todo ciega, sino que esté sometida a un sano espíritu crítico. En este caso, quisiera limitarme a señalar que, con sus palabras al menos, el Tribunal Constitucional Federal ha manifestado una sensibilidad

\footnotetext{
${ }^{33}$ Ibid., § 14 (pp. 6/9-7/9).

${ }^{34}$ Ibid., § 17 (p. 7/9).
} 
hacia la libertad religiosa superior a la mostrada por las decisiones de la mayoría del Tribunal Supremo americano. No obstante, sigo contemplando con recelo la prohibición total inicial del culto, sin posibilidad alguna de excepción basada en fuertes medidas de seguridad, puesto que se trata de un bien humano primario, esencial.

3. ¿Neutralidad o neopaganismo? La expresión religiosa institucional durante el coronavirus

No quisiera terminar estas páginas sin una referencia a una realidad que, al contacto con la muerte durante la pandemia, ha estado especialmente viva en el sentir colectivo, y que tradicionalmente se ha asociado a la llamada «dimensión objetiva de la libertad religiosa». Me refiero, como tal vez puede adivinarse, al lugar que ha ocupado la religión en la vida pública, y a las consecuencias que ello tiene para la sociedad. Debido a la propia naturaleza de este asunto, no debe abordarse tanto desde una perspectiva analítica cuanto desde una valoración más profunda y holística —como a veces se dice- sobre la sociedad.

Hace algunos meses, concretamente el Sábado Santo, publiqué un artículo en prensa que llevaba por título: "Fe, política y epidemia"35. En él, esbozaba una breve reflexión sobre el error de considerar la neutralidad abstencionista de toda manifestación política de lo religioso como la actitud propiamente acertada, desde el punto de vista jurídico-constitucional, respecto a lo sagrado. Se trata de una visión errónea, a mi entender, propiciada durante décadas por una sensación ilusoria de falta de necesidad de Dios y de autosuficiencia humana. Creo que esta percepción dista de ser una simple imaginación personal, y la ha llegado a preconizar un conocido intelectual en uno de los ensayos más difundidos de los últimos años. Me refiero a la obra de Yuval Noah Harari, significativamente titulada Homo Deus, y más en concreto, al inicio de su primer capítulo, rubricado, no menos significativamente, como The New Human Agenda. En él, el public intellectual israelí se expresaba en términos audaces:

${ }^{35}$ Vid. «Fe, política y epidemia», $A B C, 4$ de abril de 2020 (cfr. https://unav.academia.edu/FSY). 
fundación

Manuel Giménez Abad

deEstudios Parlamentarios ydelEstado Autonómico

«Los mismos tres problemas preocupaban a la gente de la China del siglo XX, de la India medieval y del Antiguo Egipto. El hambre, la plaga y la guerra estaban en la cúspide de la lista. Generación tras generación, los humanos habían rezado a todo dios, ángel y santo, y habían inventado incontables herramientas, instituciones y sistemas sociales pero continuaban muriendo a millones por la hambruna, la epidemia y la violencia-. Muchos pensadores y profetas concluyeron que el hambre, la plaga y la guerra tienen que ser una parte integral del plan cósmico de Dios para nuestra naturaleza imperfecta, y nada salvo el fin de los tiempos nos liberaría de ellas.

Sin embargo, en los albores del tercer milenio, la humanidad despierta a una asombrosa realización. La mayoría de la gente raramente piensa sobre ello, pero en las últimas décadas hemos logrado controlar completamente el hambre, la plaga y la guerra. Ciertamente, estos problemas no han sido completamente solucionados, pero han sido transformados de fuerzas de la naturaleza incomprensibles e incontrolables, en desafíos manejables.

No necesitamos rezar a ningún dios o santo que nos rescate de ellos. Sabemos muy bien lo que se necesita hacer para prevenir el hambre, la plaga y la guerra $-\mathrm{y}$ habitualmente tenemos éxito haciéndolo—» 36 .

La crisis del coronavirus hace que un fragmento como el citado -el frontispicio de un libro listado por la revista Time entre los mejores de la literatura ensayística (non-fiction) publicada en 2017- resulte sorprendente. Sin embargo, da la impresión de que la ausencia de Dios preconizada por la obra guarda una estrecha relación con el tipo de laicidad que se defiende en muchos círculos académicos, tal y como se ha revelado, como trataré de exponer, durante la pandemia. Uno de los expedientes a los que más se ha recurrido para abogar por la exclusión de Dios del ámbito institucional ha sido, a mi modo de ver, interpretar la laicidad del Estado de manera fuertemente contraria a la religión, muchas veces revistiéndola con el manto de la «neutralidad». Lejos de comportar una exclusión radical de lo sagrado del ámbito público o institucional, entiendo que la laicidad debería proyectarse en las relaciones concretas de un modo prudencial. Debería traducirse en un trato equitativo de la ciudadanía que

${ }^{36}$ Y. N. Harari, Homo Deus. A Brief History of Tomorrow, Harvill Secker, Londres, 2016, pp. 1-2. 
tuviese en cuenta tanto el pluralismo social como las propias tradiciones y la historia y raíces del propio pueblo.

De hecho, excluir todo símbolo religioso del espacio público sólo es neutral en la medida en que definimos la neutralidad equitativa, como he señalado, cual si se tratase de una especie de vacío religioso. Sin embargo, la imposición del vacío público religioso, también en el orden de los símbolos, no constituye una forma de neutralidad moral o jurídica, esto es, una forma de neutralidad en el ámbito del deber ser. Comporta, en realidad, la "exclusión" de lo religioso, una exclusión que en sí misma tiene un enorme significado e incentiva una mentalidad arreligiosa. Aducir la no discriminación entre religiones para defender semejante vacío tampoco parece un argumento válido, a mi juicio, para romper la supuesta no-neutralidad discriminatoria, dado que privilegia el vacío simbólico público, y este, como he dicho, constituye una postura cargada de significado para la sociedad en términos religiosos.

Esta forma de neutralidad, esta interpretación de la «laicidad neutral» que, recurriendo al expediente de la no discriminación, tiende a excluir lo religioso de la vida pública, se ha extendido enormemente en círculos intelectuales. Aun mantenida semper et ad semper como si se tratase de la postura más justa, la inequidad de esta neutralidad se ha revelado de manera particularmente dolorosa allí donde la realidad exigía alguna forma de plegaria pública, es decir, al trabar la sociedad contacto con la muerte. Ahora bien, cabría todavía preguntarse cuál habría de ser la expresión religiosa concreta que adoptase la plegaria pública. Este interrogante, en efecto, parece surgir de inmediato en una sociedad plural, y no creo que haya razones para dejarlo de lado.

Considero que, en muchas ocasiones, se recurre a la «neutralidad» so pretexto de la desventaja de religiones minoritarias cuando, en realidad, lo que se defiende es el avance de la irreligiosidad. Existen dos premisas, en esta línea, que una extendida mentalidad contemporánea parece desconocer: 1) de un lado, que la expresión religiosa a través de símbolos públicos tiende a cobrar un carácter concreto, y; 2) que la exclusión de lo religioso de la vida pública no es neutral. La conjunción de estas dos verdades exige optar por formas de expresión simbólico-pública de lo religioso que, sin ofender a nadie, permitan a un pueblo desarrollar una fe y unos ritos concretos. Por eso, pienso que defender nuestra herencia cristiana en la expresión simbólico-pública de la fe no va en detrimento de nadie, sino que constituye lo más natural en un país 
cuyas raíces son cristianas. El trasfondo de normalidad o, por servirme de un anglicismo, la «línea-base» (baseline) sobre la que opera la neutralidad equitativa nunca es el vacío, sino un marco histórico-cultural dado cuyo desarrollo, siempre que sea benéfico para la sociedad, constituye un legado de las generaciones pasadas a las presentes, para que lo transmitan a las futuras. Ignorar el carácter esencialmente «tradicional» — de traditio o entrega- de un pueblo y una cultura en nombre de una libertad y una neutralidad abstracta $-\mathrm{y}$, en la medida en que privilegia el vacío público, ficticia- es, desde mi punto de vista, un error, por extendido que se halle. La libertad no emerge de una «líneabase» neutral vacía, e interpretarla de ese modo puede tener consecuencias ruinosas para la civilización.

Lógicamente, la sociedad siempre tendría "de hecho" abierta la posibilidad de renunciar a sus raíces cristianas y, escudándose en la neutralidad, excluir toda referencia religiosa de lo público. La situación actual de la propia sociedad revela que, en las últimas décadas, buena parte del establishment intelectual de nuestro país ha prestado voz y energías a esta empresa de renuncia, a mi parecer tan nociva. Semejante abdicación, sin embargo, no creo que sea neutral, como he indicado, sino que constituye una opción de tipo religioso hacia una sociedad más agnóstica o atea. Toda vez que se levanta el velo de la aparente neutralidad de un espacio público sin referencias a Dios, el veredicto sobre la dignidad de esta exclusión disolvente no puede prescindir de una valoración holística, que —como en tantos otros ámbitos lleva a cabo sin ambages - el constitucionalista está también llamado a realizar. En la línea de algo que ya afirmó Dostoievski, y que han sostenido tantos pensadores a lo largo de la historia, pienso honestamente y sin la menor acritud que la exclusión de Dios ha de favorecer inexorablemente algún tipo de idolatría ${ }^{37}$, privada y pública, y una fatiga y desesperanza social de graves consecuencias en la justicia pública.

Para poner de manifiesto que las consideraciones realizadas distan de ser extemporáneas, quisiera citar un importante episodio que muestra la falta de neutralidad de la aludida exclusión de Dios, y el carácter progresivamente hostil hacia la religión misma de las interpretaciones de la laicidad. Me refiero al llamado homenaje «civil» por las víctimas de la pandemia, que ha dado lugar a

37 Son bien conocidas, en este mismo sentido, las reflexiones de Dostoievski en El adolescente. 
numerosos comentarios. Después de que el Presidente del Gobierno se negase a participar y a dotar de carácter oficial al funeral celebrado en la Catedral de la Almudena, al que asistieron SS. MM. los Reyes, se organizó un homenaje «laico", como sustitución del funeral, que muy difícilmente puede calificarse como «neutral» en términos religiosos. Coincido con muchas voces en que se aproxima más a una forma de ritual en el que la muerte constituiría, nolens volens, la última palabra.

Contemplando el ritual religioso aludido, que vino a sustituir los tradicionales funerales de Estado, me vino a la memoria un artículo de un sabio catedrático de la Sorbona, conocedor como pocos de las grandes culturas que han habitado en Occidente. En efecto, con ocasión de la crisis, Rémi Brague publicó un artículo en Le Figaro en el que se lamentaba de la ausencia de Dios de la vida pública durante la pandemia. Después de aludir al famoso «Dios ha muerto" de Nietzsche, advertía perspicazmente que, "si esto es verdad, significa que la muerte ha vencido las cosas más elevadas y santas, y ha demostrado ser más fuerte que Él». Y añadía: «y si el poder es la medida de la divinidad, ello implica que la muerte es más divina que el Dios al que derrotó. De este modo, 'Dios ha muerto' se convierte lógicamente en 'la muerte es Dios'» ${ }^{38}$.

Pienso con toda sinceridad que, entre el funeral católico y el ritual oficial, celebrado con solemnidad pública, media la distancia entre la esperanza en Dios y la proclamación de la muerte como realidad definitiva o absoluta; la distancia entre la fe que ha edificado lo más santo y grande de la civilización occidental, y una especie de vacío existencial en el que una sociedad cansada parece proclamar su desesperanza. Frente a un acto oficial y representativo, tan cargado de simbolismos, no sería honesto mirar hacia otro lado para evitar la incomodidad de afrontar la realidad, porque las expresiones simbólicas fúnebres tocan lo religioso en su mismo núcleo, dan forma a la mente de la colectividad y, toda vez que tienen carácter oficial, dejan de ser neutrales en lo que respecta al modo en que el Estado se relaciona con la religión. Más, bien,

${ }^{38}$ R. Brague, «Le méssage de la vie est d'actualité partout où la mort rôde», Le Figaro, 13 de abril de 2020: «Regardez la célèbre phrase de Nietzsche, 'Dieu est mort'. Si elle est vraie, cela signifie que la mort a eu raison de ce qu'il y a de plus haut et de plus saint, et qu'elle s'est avérée plus forte que Lui. Et si la puissance est la mesure de la divinité, cela implique que la mort est plus divine que le Dieu qu'elle a vaincu. De la sorte, 'Dieu est mort' se retourne logiquement en 'la mort est Dieu'». 
fundación

Manuel Giménez Abad

deEstudios Parlamentarios ydelEstado Autonómico

considero humildemente, y sin ánimo de ofender absolutamente a nadie, que es importante reflexionar, y proponer una vuelta a la esperanza de nuestros padres. 